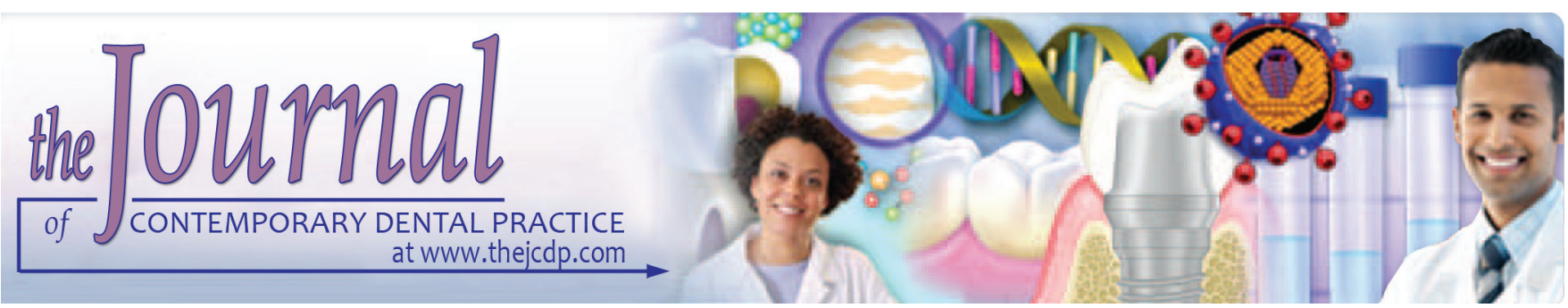

\title{
Tobacco Abuse and Associated Oral Lesions among Interstate Migrant Construction Workers
}

\author{
${ }^{1}$ Anzil KS Ali, ${ }^{2}$ Arshad Mohammed, ${ }^{3}$ Archana A Thomas, ${ }^{4}$ Shann Paul, ${ }^{5} \mathrm{M}$ Shahul, ${ }^{6} \mathrm{~K}$ Kasim
}

\begin{abstract}
Aim: The present study was conducted to assess the prevalence of tobacco use and associated oral mucosal lesions among construction workers of Cochin, Kerala, India
\end{abstract}

Materials and methods: A cross-sectional study was carried at various construction sites of Cochin and 2,163 workers were selected using multistage sampling method and were interviewed and examined. Information regarding demographic details, form, type, frequency of tobacco use, earlier attempt to quit, and willingness to quit tobacco use was obtained using predesigned questionnaire. The oral health status was recorded on the World Health Organization oral health assessment form 1997 , and the examination was carried out under natural light using mouth mirrors and probe. Data thus collected were analyzed using Statistical Package for the Social Sciences version 17 (Chicago, Illinois, USA) statistical software package. Chisquare test was applied.

Results: Among the 2,163 workers, 1,952 were tobacco users and 211 were nonusers. Among the users, 1,021 use smokeless form, 372 use smoked form, and 559 use both. Premalignant lesions/conditions were more commonly seen with tobacco habit, with leukoplakia (14.75\%) being the most common followed by oral submucous fibrosis in $201(9.3 \%)$, candidiasis in $123(5.7 \%)$, ulceration in $131(6.05 \%)$, abscess in $59(2.73 \%)$,

\footnotetext{
${ }^{1,4}$ Department of Public Health Dentistry, St. Gregorios Dental College, Chelad, Ernakulam, Kerala, India

${ }^{2}$ Department of Public Health Dentistry, Kannur Dental College Anjarakandy, Kannur, Kerala, India

${ }^{3}$ Department of Pedodontics and Preventive Dentistry, St. Gregorios Dental College, Chelad, Ernakulam, Kerala, India

${ }^{5}$ Department of Surgical Diagnostics Sciences, College of Dentistry, Dar Al Uloom University, Riyadh, Kingdom of Saudi Arabia

${ }^{6}$ Department of Oral Pathology and Microbiology, Kannur Dental College, Kannur, Kerala, India

Corresponding Author: Anzil KS Ali, Department of Public Health Dentistry, St. Gregorios Dental College, Chelad Ernakulam, Kerala, India, e-mail: anzilksali@gmail.com
}

smokers palate in $58(2.68 \%)$, lichen planus in $21(0.97 \%)$, and malignant tumor in $2(0.1 \%)$.

Conclusion: Commonness of abusive habits and oral premalignant lesions or conditions was considerable among the workers. Control and early diagnosis through workplace screening are the major backbones for the control of oral cancer.

Clinical significance: Building workers are unprotected from various health hazards at workplace. Lack of access to health services makes the situation unsatisfactory. Poor literacy and low socioeconomic status have resulted in practice of tobacco, smoking, and chewing in the majority of them. Hence, it is our responsibility to find and guide them with a proper oral health education.

Keywords: Cochin, Construction workers, Migrant workers, Tobacco users.

How to cite this article: Ali AKS, Mohammed A, Thomas AA, Paul S, Shahul M, Kasim K. Tobacco Abuse and Associated Oral Lesions among Interstate Migrant Construction Workers. J Contemp Dent Pract 2017;18(8):695-699.

Source of Support: Self-financed by the Department of Public Health Dentistry, St. Gregorios Dental College.

Conflict of Interest: None

\section{INTRODUCTION}

The intense tie between oral malignancies with tobacco use is well confirmed and documented. Tobacco user's count in the world has been reckoned at 1.2 billion, which is presumed to mount to 1.6 billion during $2020 .^{1}$

Kerala is a distinctive region in India with more than 50 of its total population (32 million) living in a nonrural area with low population growth. ${ }^{2}$ Approximately 2.5 million migrant laborers from other states (interstate migrants) are working in Kerala. ${ }^{3}$ In 2016, this figure rose to 4 million. ${ }^{4}$ Kerala has been observing large invasion of migrant laborers not only from the nearby states but also from West Bengal, Odisha, Bihar, Uttar Pradesh, Uttarakhand, Assam, Manipur, and even from Nepal. ${ }^{5}$ 
Building workers are unprotected from various health hazards at workplace. ${ }^{6}$ The work is tough, manual work, usually under extreme conditions, such as unpleasant climatic conditions; the nature of work, working hours, lesser income, extreme living standards with short supply of basic services and detachment from their families, lack of job surety, and lack of access to health services make the situation unsatisfactory. They are mostly migrants from isolated villages, often are illiterate, have poor language skills, and are not vigilant about different preventive measures. $^{7}$

Use of tobacco products is widely seen among construction workers in Cochin. Poor literacy and low socioeconomic status have resulted in the practice of tobacco, smoking, and chewing in the majority of them. In industrialized countries, smoking is proved to be the leading cause of 40 to $45 \%$ of all cancer deaths among males, around 90 to $95 \%$ deaths secondary to pulmonary cancers, approximately $85 \%$ of deaths due to oral malignancy, and around $35 \%$ of deaths due to underlying cardiovascular diseases. ${ }^{8}$ As there has been no such studies conducted on the construction workers regarding the prevalence of oral lesions due to tobacco using habits, an attempt was done to assess the prevalence of tobacco habits and associated lesions among the construction workers of Cochin.

\section{MATERIALS AND METHODS}

A cross-sectional study was conducted at different construction sites in Cochin from the March to July 2016. Permission from the Labour Commissioner of the Ernakulum district was obtained before the study. Permission for the study was granted by the Ethical Review Board of St. Gregorios Dental College (dated January 28, 2016, NO. SGDC/PHD/ERB/173R/2016). Written informed consent was obtained from each participant before examination. Workers between 14 and 55 years of age, who were present and willing for the survey, were included. Workers below 15 years of age and above 54 years of age were excluded. Workers were interviewed by trained interviewers through prepared questionnaire to collect the data that included name, age, gender, duration of tobacco use, type of tobacco used, and attempt for quitting tobacco use. Each item was a closedended question which was translated from English into Malayalam, backtranslated, and then, both versions were checked for reliability by the test-retest method. Each item was a multiple choice question with a single answer. There was no skip pattern; no multiple response questions and all questions were required to be answered. The questions were written at a language level that should have allowed comprehension by even the youngest participants.

Responses were measured based on the correct answer provided by each participant. Twenty participants were pretested with the questionnaire to assess translation accuracy, validity, and suitable modifications before field administration. Reliability was assessed using Cronbach's alpha internal consistency coefficient (the value averaged 0.82 ). Study population was selected using multistage sampling method. Among 13 municipalities in Cochin, 5 (Kothamangalam, Muvattupuzha, Perumbavoor, Angamaly, and Aluva) were selected. Sample size was calculated by taking the least prevalence of oral precancerous lesion $n=4 p q / d^{2}$, where $p=$ prevalence, $q=100-p$, $\mathrm{d}=$ allowable error (5-20\% of $\mathrm{p}$ ) and hence, 2,163 was the sample size. From the selected five municipalities, various construction sites were randomly selected and from them 2,163 construction workers were selected.

After getting the necessary sanction from the labor commissioner, group leader of each construction site was approached and intention of the study was explained in detail. Investigator explained the procedure to the workers who were present at the site and they were interviewed and examined under his presence. Type I clinical examination was carried out. One trained and calibrated examiner performed all clinical examinations, with the trained recorder marking the observations. Before starting the survey, training was done for the examiner and the recorder in the Department of Public Health Dentistry, St. Gregorios Dental College. Further, the participants were examined by trained examiners for any oral lesions associated with their habit of tobacco usage. Lesions were confirmed by a specialist in oral medicine and radiology. Data were analyzed using Statistical Package for the Social Sciences version 17.0. Descriptive statistics included percentages, frequencies, and Chi-square tests, to find out significant mean differences $(p<0.05)$.

\section{RESULTS}

Table 1 shows that among the 2,163 construction workers, $1,982(91.63 \%)$ were males and $181(8.37 \%)$ were females. The majority (37.4\%) of construction workers belonged to the age group 25 to 34 years, $69.81 \%$ of the workers were migrants; $59.13 \%$ were married, $40.96 \%$ were Hindus, $34.9 \%$ were illiterate, $69.81 \%$ were migrants, and $68.47 \%$ were from above poverty line.

Table 2 reveals that 1,952 (90.25\%) were tobacco users which include 1,833 (84.74\%) males and 119 (5.51\%) females. Among the users, 682 (34.94\%) used tobacco for about 6 to 10 years. Among the 1,952 tobacco users, 1,021 (52.3\%) used smokeless form of tobacco, 372 (19.06\%) used smoked form of tobacco, and 559 (28.64\%) used both. Among the smokers, 311 (15.93\%) used cigarette and 249 (12.76\%) used bidis more often. Among the chewers, 623 (31.91\%) used khaini, 558 (28.59\%) used pan masala (Pan Parag), and 211 (10.81\%) used betel quid with tobacco more often. 
Tobacco Abuse and Associated Oral Lesions among Interstate Migrant Construction Workers

\begin{tabular}{|c|c|}
\hline Parameters & Number of workers $(n=2,163)$ \\
\hline \multicolumn{2}{|l|}{ Gender } \\
\hline Male & $1,982(91.63 \%)$ \\
\hline Female & $181(8.37 \%)$ \\
\hline \multicolumn{2}{|l|}{ Age group (years) } \\
\hline $15-24$ & $581(26.86 \%)$ \\
\hline $25-34$ & $809(37.4 \%)$ \\
\hline $35-44$ & $484(22.38 \%)$ \\
\hline $45-54$ & $289(13.36 \%)$ \\
\hline \multicolumn{2}{|l|}{ Marital status } \\
\hline Married & $1,279(59.13 \%)$ \\
\hline Unmarried/separated & $884(40.87 \%)$ \\
\hline \multicolumn{2}{|l|}{ Religion } \\
\hline Hindu & $886(40.96 \%)$ \\
\hline Muslim & $693(32.04 \%)$ \\
\hline Christian & $397(18.36 \%)$ \\
\hline Others & $187(8.64 \%)$ \\
\hline \multicolumn{2}{|l|}{ Education } \\
\hline Illiterate & $755(34.9 \%)$ \\
\hline Primary & $786(36.34 \%)$ \\
\hline Secondary & $455(21.04 \%)$ \\
\hline Higher secondary & $159(7.35 \%)$ \\
\hline Graduate & $8(0.37 \%)$ \\
\hline \multicolumn{2}{|l|}{ State of origin } \\
\hline Kerala & $653(30.19 \%)$ \\
\hline West Bengal & $845(39.07 \%)$ \\
\hline Bihar & $339(15.67 \%)$ \\
\hline Assam & $178(8.23 \%)$ \\
\hline Others & $148(6.84 \%)$ \\
\hline \multicolumn{2}{|l|}{ Socioeconomic status } \\
\hline APL & $1,481(68.47 \%)$ \\
\hline BPL & $682(31.53 \%)$ \\
\hline
\end{tabular}

Table 2: Distribution of participants according to tobacco usage

\begin{tabular}{|c|c|c|}
\hline Parameters & Subcategory & $\begin{array}{l}\text { Number of } \\
\text { workers (\%) }\end{array}$ \\
\hline \multirow{6}{*}{$\begin{array}{l}\text { Tobacco users } \\
(\mathrm{N}=2163)\end{array}$} & Users & \\
\hline & Male $(1,833)$ & $1,952(90.25 \%)$ \\
\hline & Female (119) & \\
\hline & Non-users & \\
\hline & Male (149) & $211(9.75 \%)$ \\
\hline & Female (62) & \\
\hline \multirow{4}{*}{$\begin{array}{l}\text { Duration of use } \\
\text { (years) }(n=1952)\end{array}$} & $\leq 5$ & 279 (14.29\%) \\
\hline & $6-10$ & $682(34.94 \%)$ \\
\hline & $11-15$ & $607(31.1 \%)$ \\
\hline & $\geq 16$ & $384(19.67 \%)$ \\
\hline \multirow{3}{*}{$\begin{array}{l}\text { Form of tobacco } \\
(n=1952)\end{array}$} & Smokeless form & $1,021(52.31 \%)$ \\
\hline & Smoked form & $372(19.06 \%)$ \\
\hline & Both & $559(28.63 \%)$ \\
\hline \multirow{5}{*}{$\begin{array}{l}\text { Type of tobacco } \\
\text { used more often } \\
(\mathrm{n}=1952)\end{array}$} & Bidi & $249(12.76 \%)$ \\
\hline & Cigarette & $311(15.93 \%)$ \\
\hline & Pan & $558(28.59 \%)$ \\
\hline & Betel quid & $211(10.81 \%)$ \\
\hline & Khaini and other forms & $623(31.91 \%)$ \\
\hline
\end{tabular}

$\mathrm{N}$ : Total workers studied; $\mathrm{n}$ : Tobacco users

shows the penchant of younger population toward Khaini chewing. Pan masala prevalence $(28.59 \%)$ was preferred next to khaini chewing, and this was mostly practiced by middle-aged population (25-34 years).

Among the 1,952 tobacco users, 218 (11.17\%) users tried to quit tobacco earlier and $618(31.66 \%)$ were willing to quit tobacco use (Graph 3).

Table 3 reveals that among the 2,163 workers, 1,249 workers were found to have healthy oral mucosa.

Smokeless form of tobacco was used more among the age group 15 to 34 years and smoked form among age group 35 to 54 years (Graph 1).

Graph 2 depicts that the common habit among the study group was khaini chewing (31.91\%), especially among the younger age group of 15 to 24 years. This

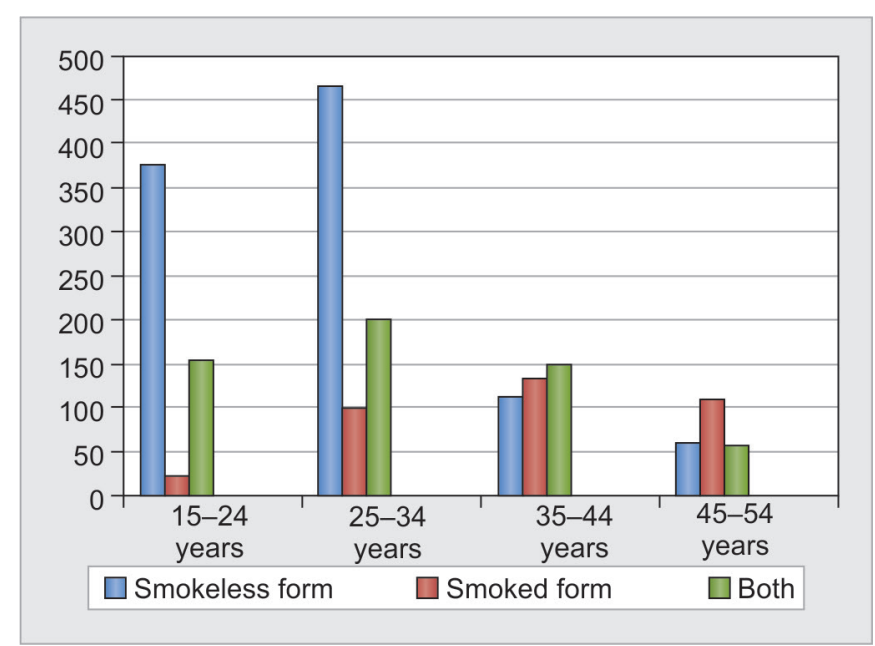

Graph 1: Age-wise distribution of construction workers based on the form of tobacco used
Premalignant lesions/conditions were more commonly seen with tobacco chewing habit, with leukoplakia $(319,14.75 \%)$ being the most common followed by oral submucous fibrosis (OSMF; 201, 9.3\%), ulceration (131, 6.05\%), candidiasis $(123,5.7 \%)$, abscess $(59,2.73 \%)$, smoker's palate $(58,2.68 \%)$, lichen planus $(21,0.97 \%)$, and malignant tumor $(2,1 \%)$.

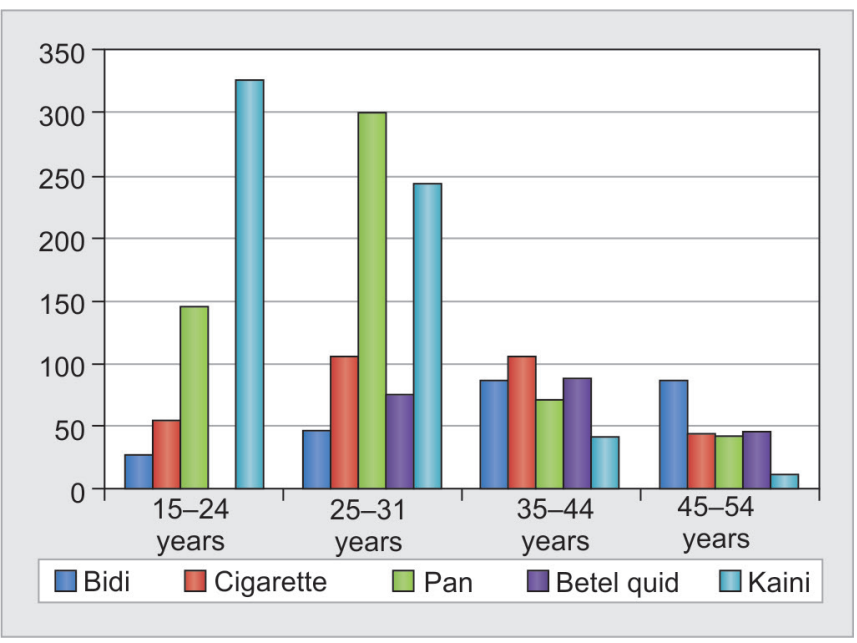

Graph 2: Age-wise distribution of construction workers based on the different types of tobacco 


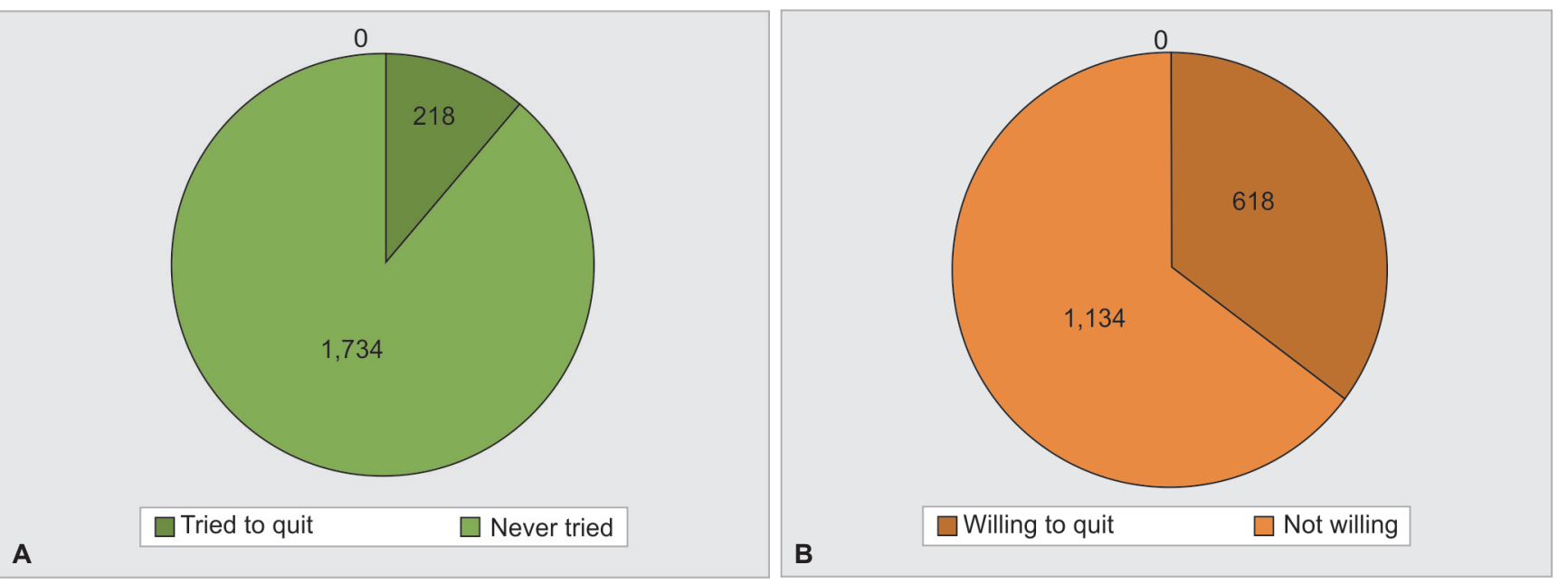

Graph 3: Distribution of participants according to their attempt and willingness to quit tobacco

Table 3: Distribution of oral mucosal lesions among the participants

\begin{tabular}{llll}
\hline & $\begin{array}{l}\text { Nontobacco } \\
\text { users } \\
(n=211)\end{array}$ & $\begin{array}{l}\text { Tobacco } \\
\text { users } \\
(n=1,952)\end{array}$ & $\begin{array}{l}p \text {-value } \\
\text { Oral mucosal lesions }\end{array}$ \\
\hline No abnormal condition & 122 & 1,127 & $0.001^{* *}$ \\
Malignant tumor & 0 & 2 & 0.10 \\
Leukoplakia & 0 & 319 & $0.001^{* *}$ \\
Lichen planus & 3 & 18 & 0.02 \\
Ulceration & 53 & 78 & $0.01^{*}$ \\
ANUG & 0 & 0 & 0 \\
Candidiasis & 15 & 108 & $0.001^{* *}$ \\
Abscess & 18 & 41 & $0.01^{*}$ \\
Smokers palate & 0 & 58 & $0.001^{* *}$ \\
OSMF & 0 & 201 & $0.001^{* *}$
\end{tabular}

ANUG: Acute necrotizing ulcerative gingivitis; OSMF: Oral submucous fibrosis; * Statistically significant; **Highly Significant

\section{DISCUSSION}

Current study was conducted among construction workers in various parts of Ernakulum district to estimate the prevalence of tobacco abuse and associated oral lesions in them. The reason for preferring construction workers was that instead of being the most integral part of urbanization in the city, they are victims of occupation involving hard labor, poverty, and low literacy rate coupled with ignorance.

A total of 2,163 construction workers were interviewed and examined. Among them, the majority $(69.81 \%)$ are migrants. The majority of the migrants belonged to the age group 15 to 34 years; $37.4 \%$ of the total workers belongs to the age group 25 to 34 years. Among the 2,163 workers, 1,952 were tobacco users and 211 were nonusers. Among the users, 1,021 used smokeless form, 372 used smoked form, and 559 used both. Premalignant lesions / conditions were more commonly seen with tobacco habit, with leukoplakia $(14.75 \%)$ being the most common followed by OSMF in 201 (9.3\%), candidiasis in 123 (5.7\%), ulceration in $131(6.05 \%)$, abscess in $59(2.73 \%)$, smokers palate in $58(2.68 \%)$, lichen planus in $21(0.97 \%)$, and malignant tumor in $2(0.1 \%)$.

The overall prevalence of tobacco use in our study was $90.25 \%$, which was higher than other reported studies by earlier community-based studies of tobacco use from other parts of the country. ${ }^{9,10}$ Tobacco is the leading cause of mortality globally and in India.

Tobacco products are used mostly in chewed and smoked form. The common habit among the study group was khaini chewing $(31.91 \%)$, especially among the younger age group of 15 to 24 years. This shows the penchant of younger population toward khaini chewing. Pan masala prevalence $(28.59 \%)$ was preferred next to khaini chewing, and this was mostly practiced by middle-aged population (25-34 years); this was similar in comparison with the study conducted by Vikneshan et al. ${ }^{10}$

This study shows that $88.83 \%$ never tried to quit tobacco usage and $58.09 \%$ were not willing to quit tobacco. This is a clear indication of lack of tobacco cessation programs among the downtrodden workers.

Among the total study participants, 914 (42.27\%) had oral mucosal lesions which is higher when compared with study conducted among interstate migrant workers $(36.3 \%)$ and fishermen population (14.9\%) in Kerala. ${ }^{11,12}$ This rate is less when compared with $44.1 \%$ reported by Reddy et al. ${ }^{13}$ Oral leukoplakia (14.75\%) and OSMF $(9.3 \%)$ were the prevalent oral mucosal lesions found in participants who had those habits, which is similar with the studies conducted by Prashant B Patil (8.2 and 7.1\% respectively). ${ }^{14}$ Our study confirmed the fact that tobacco chewing is the strongest risk for precancerous lesions. This clearly states that as the number and chronicity of oral habits increase, the number and severity of oral lesions also increases. There was a statistically significant association between type of tobacco habits and tumor.

The high incidence of tobacco consumption and related oral mucosal lesions among migrants has serious 
health indications. The extensive use of tobacco products will multiply the incidence of tobacco-related cancer in the state and can encumber the state's health system. ${ }^{15}$

The sale of smokeless tobacco has been prohibited in the state. The present study showed that in spite of the ban, the use of smokeless tobacco products was high among male migrants. The study also materializes that one-third of smokers started smoking recently within last 1 year while they had been using smokeless tobacco for many years. This behavioral change may have been due to the impact of ban on smokeless tobacco. It is noticed that migration increases the use of tobacco as the prevalence of use is higher than prevalence in their native state. This may be associated with various stress factors related to migration.

The strength of the study was that to the best of our knowledge, this was the first study done in the state to assess the burden of tobacco use and oral mucosal lesions among migrant workers in Kerala. However, as the workers are not registered in state labor registries, there was an absence of sampling frame for random sampling. The convenient sampling of the study participants may affect the generalization of the results of the study to whole migrant population.

To control the situation, health promotion activities directed toward tobacco and alcohol cessation should be actively carried out among the migrant laborers by the health staffs of primary health centers in their field area. Behavior changing communication materials for tobacco and alcohol cessation should be made available in their native languages. To control the use of smokeless tobacco products, strict enforcement of ban on sales of smokeless tobacco can also be done. For prevention, early detection, and control of oral cancers, the routine health camps organized by the health departments for migrants should also include screening for oral cancer.

\section{CONCLUSION}

Compared with the general population, tobacco abuse was higher in construction workers in which $69.81 \%$ were migrants. Tobacco abuse was commonly seen in the young population of age group 15 to 34 years. Prevention of tobacco use in its early stage leads to improvement of symptoms, so it is of high need that these workers have to be educated regarding ill effects of tobacco on their oral and general health. Therefore, intervention programs to discourage the use of tobacco risky habits should be a public health priority.

\section{ACKNOWLEDGMENT}

The authors acknowledge the contributions of Public Health Dentistry interns and camp coordinators of St. Gregorios Dental College in collecting the data.

\section{REFERENCES}

1. Purnamma R. Profile of tobacco and non-tobacco related cancer patterns in males of tertiary care hospitals in Guntur district, Andhra Pradesh. IOSR J Dent Med Sci 2015 Mar;14(3):33-37.

2. Government of India. Census of India. Kerala Size, Growth and Rural-Urban Distribution of Population. Ch. II. New Delhi: Government of India; 2011. Available from: http:/ / www.censusindia.gov.in/2011-prov-results / / kerala / Chapter_II.pd. Accessed on 19/3/2017.

3. India's National Magazine Study on the Domestic Migrant Labour in Kerala. 2015. Available from: http:/ /www.ministerlabour.kerala.gov.in/index.php?option=com_content\&vie $\mathrm{w}=$ article\&id=120:study-on-the-domestic-migrant-labour-in kerala\&catid=34:frontslider. Accessed on 25/3/17.

4. Wikipedia, the free encyclopedia. Available from: https:// www.en.wikipedia.org/wiki/Migrant_labourers_in_Kerala. [cited 2016 Aug 13].

5. Kumar NA. Vulnerability of migrants and responsiveness of the state: the case of unskilled migrant workers in Kerala. Kerala: India Responsiveness of the State; 2011. Available from: http:/ / www.csesindia.org/adHYPERLINK"http:/ / www.csesindia.org/admin/modules/cms/docs/publication/29.pdf"min/modules/cms/docs/publication/29.pdf. Accessed on 28/3/17.

6. Kulkarni GK. Construction industry: More needs to be done. Indian J Occup Environ Med 2007;11(1):1-2.

7. Jayakrishnan T, Thomas B, Rao B, George B. Occupational health problems of construction workers in India. Int J Med Public Health 2013 Oct;3(4):225-229.

8. Aljabab MA, Aljbab AA, Patil SR. Evaluation of oral changes among tobacco users of Aljouf province, Saudi Arabia. J Clin Diagn Res 2015 May;9(5):58-60.

9. Kumar YS, Acharya S, Pentapati KC. Prevalence of oral potentially malignant disorders in workers of Udupi taluk. S Asian J Cancer 2015 Jul-Sep;4(3):130-133.

10. Vikneshan M, Ankola AV, Hebbal M, Sharma R, Suganya M. Patterns of tobacco usage and oral mucosal lesions of industrial workers: A cross sectional study. Austin J Public Health Epidemiol 2016 Jan;3(1):1029.

11. Aslesh OP, Paul S, Paul L, Jayasree AK. High prevalence of tobacco use and associated oral mucosal lesion among interstate male migrant workers in urban Kerala, India. Iran J Cancer Prev 2015 Dec;8(6):e3876.

12. Anzil K, Mathews J, Sai AG, Kiran M, Kevin S, Sunith S. Prevalence of deleterious oral habits and oral mucosal lesions among fishermen population of Mahe, South India. J Contemp Dent Pract 2016 Sep;17(9):745-749.

13. Reddy SS, Prashanth R, Yashodha Devi BK, Chugh N, Kaur A, Thomas N. Prevalence of oral mucosal lesions among chewing tobacco users: a cross-sectional study. Indian J Dent Res 2015 Dec;26(5):537-541.

14. Patil PB, Bathi R, Chaudhari S. Prevalence of oral mucosal lesions in dental patients with tobacco smoking, chewing, and mixed habits: a cross-sectional study in South India. J Family Community Med 2013 May;20(2):130-135.

15. Patil S, Yadav N, Patil P, Kaswan S. Prevalence and the relationship of oral mucosal lesions in tobacco users and denture wearers in the North Indian population. J Family Community Med 2013 Sep;20(3):187-191. 